\title{
Condição cognitiva de crianças de zona rural
}

\author{
Rural children cognitive state
}

\author{
Carmen Elvira FLORES-MENDOZA' \\ Elizabeth do NASCIMENTO'
}

\section{Resumo}

O estudo objetivou analisar a situação cognitiva de crianças da zona rural. Participaram do estudo 144 crianças com idade entre seis e onze anos de idade de uma vila rural, de situação socioeconômica bastante precária, situada na zona norte do Estado de Minas Gerais. Empregaram-se as Matrizes Progressivas de Raven e os subtestes Aritmética, Dígitos e Código do Teste Wechsler Intelligence Scale for Children-III. Os resultados mostraram, de forma geral, que as diferenças de desempenho nos testes estão associadas à idade apenas em grupos de menor idade. A comparação de uma subamostra de crianças rurais $(n=59)$ com uma de crianças urbanas ( $n=143$ ) de sete e oito anos de idade, com equivalência de nível de escolaridade, apontou uma diferença de 30 pontos de quociente intelectual no teste Raven e uma diferença média de 16,18 pontos de quociente intelectual nos subtestes aritmética e dígitos. Conclui-se que déficits ambientais afetam com maior intensidade a inteligência fluida do que a inteligência cristalizada.

Unitermos: crianças em idade escolar; inteligência cristalizada; zona rural, Brasil.

\begin{abstract}
The study had as objective to raise information about the rural children cognition. This sample was composed by 144 rural children, aged from 6 to 11 years old, who live in a very poor village localized in the north of Minas Gerais State. The Coloured Matrices Progressives test was applied as well as three subtests from Wechsler Intelligence Scale for Children-III [Arithmetic, Digit Span and Code]. The results showed that, in general, the differences in performance on these tests were associated to age only in younger groups. The comparison between the rural children sample $(n=59)$ to the urban children one $(n=143)$, aged from 7 to 8 years old and all of them academic level equivalent, pointed 30 points of intellectual quotient difference on Raven, and 16.18 points of intellectual quotient difference on two verbal subtests [Arithmetic and Digit Span]. It was concluded that environmental deficits affect more the fluid intelligence than the crystallized intelligence.
\end{abstract}

Uniterms: preschoolstudents; crystallized intelligence; rural zone, Brazil.

É sobejamente conhecido o papel ubíquo da inteligência no alcance de conquistas sociais, comportamentais e educacionais (Gottfredson, 1997; Jensen, 1998; Neisser et al., 1996). Tal conhecimento advém das pesquisas de associação entre o desempenho em testes de inteligência e critérios externos. Contudo os índices de associação podem oscilar dependendo de variáveis mediadoras (sociais e biológicas), como o grau de nutrição, a procedência geográfica, o grau de escolaridade, o nível econômico e o tipo de escola

$\boldsymbol{\nabla \nabla \nabla \nabla}$

1 Universidade Federal de Minas Gerais, Departamento de Psicologia, Laboratório de Avaliação das Diferenças Individuais. Av. Antônio Carlos, 6627, 31270-901, Pampulha, Belo Horizonte, MG, Brasil. Correspondência para/Correspondence to: C.E. FLORES-MENDOZA. E-mail: <carmencita@fafich.ufmg.br>. Agradecimentos: Aos alunos Tathiana Martins Carvalho, Ana Carolina Zeferino, Talitha R. C. Veneroso, Fernanda M. Franco, Thiago M. Villanova e Marcela Mansur-Alves por auxiliarem na avaliação das crianças. 
(particular ou pública) que os sujeitos freqüentam (Neisser, 1998).

Uma outra variável igualmente associada à inteligência é a influência da modernização. Para investigá-la, a comparação do desempenho intelectual de pessoas residentes na zona rural com o desempenho de pessoas da zona urbana é motivo de interesse da comunidade científica (Sigman \& Whaley, 1998; William, 1998).

Nesse sentido, é fato conhecido que, desde o início da segunda metade do século passado, observa-se uma crescente migração populacional do campo para a cidade, pois é na cidade que se encontram meios de comunicação, transporte, educação, cuidados médicos e sanitários muito mais sofisticados. O aumento da urbanização, e com ela, a modernização, implica, portanto, intervenções ambientais que melhoram as condições de vida da população. Tais melhorias se refletem nas menores taxas de mortalidade infantil, na maior longevidade da população e no maior controle de doenças endêmicas nas zonas urbanas. Entre as melhorias psicológicas, a variável especialmente a ser destacada é o aumento intelectual da população chamado de "efeito Flynn"(Flynn, 2003).

O ganho intelectual tem-se refletido no aumento das pontuações em testes de inteligência durante o século XX e ele tem sido identificado em vários países, principalmente naqueles com alto desenvolvimento socioeconômico. A taxa de crescimento intelectual gira em torno de três pontos de quociente intelectual (QI) por década, estando o ganho maior relacionado mais aos testes de inteligência fluida (ex. Raven) do que aos de inteligência cristalizada (ex. Wechsler Intelligence Scale for Children -WISC).

A inteligência fluida seria a capacidade de resolução de problemas para os quais não houve uma prévia aprendizagem; enquanto que a inteligência cristalizada refere-se à capacidade de operar eficientemente as informações apreendidas (Cattell, 1971).

As explicações dadas pela comunidade científica para o aumento intelectual foram agrupadas por Flynn (2006) em duas amplas abordagens: hipótese nutricional e hipótese da estimulação cognitiva. A primeira diz respeito à influência dos melhores padrões nutricionais 14 e cuidados médicos da população. A segunda, à presença e à disponibilidade de desafios cognitivos apresentados pela televisão, jornais, computador, internet, entre outros; assim como à demanda cognitiva de trabalhos cada vez mais complexos.

Essas abordagens que explicam as diferenças cognitivas entre gerações podem ser também levantadas para entender as diferenças cognitivas intragerações. As pesquisas transculturais, por exemplo, apontam que habitantes de países socioeconomicamente desfavorecidos ou residentes em ambiente rural apresentam quase sempre baixos escores em testes de inteligência. Esses estudos dizem respeito a países como Nigéria (Fahrmeier, 1975); Gana (Glewwe \& Jacoby, 1992) ou Kenya (Sternberg et al., 2001), países conhecidos pelos baixos índices de desenvolvimento humano.

A relação entre desenvolvimento social e inteligência tem se estendido até as nações. É o que mostra o trabalho de Lynn e Vanhanen (2002). Os autores identificaram uma correlação positiva entre a riqueza das nações e o nível médio de inteligência de suas populações. Para tanto, Lynn levantou dados da renda per capita de 150 países (incluindo o Brasil) e o QI médio dos seus habitantes conforme resultados expostos nos manuais de testes de inteligência padronizados e adaptados para cada País. O índice encontrado foi de 0,70. Tal resultado foi interpretado como: quanto maior a inteligência dos cidadãos, maior é a sua riqueza. Contudo o raciocínio inverso também pode ser correto: quanto maior o desenvolvimento socioeconômico, maior o nível intelectual dos seus habitantes, pois é bastante difícil estabelecer quais são as variáveis independentes e quais são as dependentes.

Nesse sentido, pode-se citar o estudo de Alderman, Behrman, Khan, Ross e Sabot (1996). Os autores investigaram duas coortes de pessoas, na faixa etária entre 20 e 24 anos e entre 30 e 44 anos de idade, de 43 vilas rurais de quatro cidades do Paquistão. As vilas apresentavam diferenças na disponibilidade e qualidade de escolas. Essas diferenças, segundo a análise dos autores, estavam associadas às diferenças regionais em escolaridade e às diferenças no alcance cognitivo das coortes.

No caso do Brasil, o censo do Instituto Brasileiro de Geografia e Estatística de 2000 informa que a população urbana é 4,3 vezes maior que a população rural. Esse aumento da urbanização teve início na década 
de 1960. Atualmente, a urbanização do país alcança 81,23\% de todo o território. Especificamente em Minas Gerais, estado no qual se realizou o presente estudo, a população urbana cresceu de 8.982.134 para 14.651.164, no período de 1980 a 2000 (taxa de crescimento de 2,47); enquanto a população rural diminuiu de 4.396.419 para 3.215.238 no mesmo período (taxa de decréscimo de -2,30). O grau de urbanização atual do estado é de 82,00\%. Por outro lado, em nível nacional as taxas de analfabetismo e de mortalidade infantil da zona rural são maiores que as da zona urbana e com o passar dos anos observa-se uma diminuição das diferenças desses índices nos estados da Região Sudeste (www.ibge.gov.br).

No território mineiro, principalmente no norte do estado, existem pequenas vilas rurais dificilmente encontráveis em grandes censos demográficos e que se caracterizam pela extrema pobreza de seus habitantes. Nesse sentido, se a condição social acompanha a situação cognitiva, torna-se necessário, em nível social e acadêmico, avaliar e comparar a distância cognitiva que separa os habitantes da zona rural, especialmente os de idade escolar, dos da zona urbana.

Os registros no Brasil envolvendo diferenças intelectuais associadas à modernização urbana são quase inexistentes (Carelli, 1994). A maioria das investigações nacionais sobre diferenças intelectuais e sua relação com variáveis sociais ou acadêmicas pode ser encontrada no período do início do século passado até a década de 1970. Após esse período, é bastante difícil encontrar estudos amplos e sistemáticos (Flores-Mendoza, 2006).

Contudo existe um estudo bastante informativo, indiretamente relacionado ao desenvolvimento cognitivo, que trata da relação entre saúde e escolaridade de crianças do ensino fundamental de áreas rurais do estado do Ceará. Esse estudo foi desenvolvido por Gomes-Neto, Hanushek, Leite e Frota-Bezerra (1997). Eles aproveitaram os dados do único levantamento efetuado na década de 80 de estudantes rurais de três estados do nordeste pelo programa de intervenção governamental chamado de Projeto de Educação Básica para o Nordeste - Programa de Extensão e Melhoria para o Meio Rural (EDURURAL). Gomes-Neto et al. (1997) analisaram especificamente os dados de avaliação de 378 alunos rurais do estado do Ceará matriculados na segunda série em 1985 e que continuaram em 1987. As variáveis independentes consistiram de medidas antropométricas (peso, altura e espessura do tríceps), anos de escolaridade dos pais, acuidade visual e motivação para continuar os estudos. As variáveis dependentes foram a interrupção escolar (não continuação em 1987) e a promoção escolar (matrícula na quarta série em 1987 como era esperado). Os resultados de regressão apontaram que as variáveis relacionadas à saúde (acuidade visual e medidas antropométricas) prediziam significativamente a possibilidade de a criança interromper a escola e a possibilidade de ser promovida nas séries escolares. Os autores concluíram que em ambientes muitos pobres, como é o caso das zonas rurais, uma melhor nutrição melhora as funções cognitivas e, portanto, a aprendizagem.

A oportunidade de atualizar as informações sobre desempenho cognitivo de crianças de zonas rurais surgiu no segundo semestre de 2004, quando o Laboratório de Avaliação das Diferenças Individuais (LADI) foi contatado para colaborar em um projeto coordenado pela Escola de Enfermagem da Universidade Federal de Minas Gerais (UFMG). O objetivo geral era pesquisar a situação cognitiva das crianças de uma zona rural situada no norte do estado, identificada como área endêmica pelo alto índice (80\%) de infecção dos habitantes com o Ancilostomo duodenale e Necator americanus (tipo de larva conhecida popularmente no Brasil como "amarelão" e bastante freqüente em áreas não urbanas). Na ocasião, foi solicitada a avaliação cognitiva de crianças entre seis e doze anos de idade, cujo planejamento e resultados serão descritos a seguir.

\section{Método}

A vila rural onde foi feita a coleta de dados está situada ao norte do Estado de Minas Gerais, a quase 900 quilômetros de Belo Horizonte. Sua população é de aproximadamente 2.500 habitantes, estimativa feita pelos agentes educativos dessa cidade, pois ela não consta em qualquer censo habitacional. Os agentes educacionais dividem a vila em zonas periféricas e centro. As zonas periféricas localizam-se a aproximadamente vinte quilômetros do centro. No centro, não há asfalto, hospital, posto de correio, bancário ou farmácia. A maioria absoluta dos habitantes (95\%) não dispõe de energia elétrica. Somente há um posto de telefone público e uma parada de ônibus intermunicipal. 
Os médicos visitam a cidade uma vez por semana. Existem duas escolas no centro da cidade, sendo a primeira (recentemente inaugurada) destinada a crianças da pré-escola até a $4^{a}$ série. A segunda escola destina-se a alunos da $5^{a}$ até a $8^{a}$ série.

As zonas periféricas são divididas em números, mas se desconhece o critério da divisão. Em cada zona periférica há somente uma pequena escola com uma sala de aula, uma cozinha e um dormitório para a dupla de professores que se hospeda de segunda a sexta-feira. Tanto nas escolas do centro quanto nas da periferia existem dois turnos escolares (matutino e vespertino).

A população que habita a vila trabalha quase que exclusivamente na lavoura. A dieta básica é constituída de arroz, feijão, mandioca, milho e macarrão. Quase não há consumo de carne ou peixe, ocorrendo na maioria das vezes apenas uma refeição. A maioria das crianças das zonas periféricas desconhece outras vilas, tendo como referência apenas a própria. Em cada zona periférica as casas ficam bastante dispersas e distantes do centro da vila. Em geral, as crianças caminham a pé por um período aproximado de uma a duas horas para chegarem à escola.

Foram testadas 144 crianças entre seis e onze anos e onze meses de idade (69 meninas e 75 meninos), moradoras de três zonas periféricas $(3,4$ e 7) e da área central da vila rural.

\section{Materiais}

A fim de possibilitar a comparação de desenvolvimento cognitivo entre crianças rurais e urbanas, escolheram-se provas que demandam inteligência fluida e cristalizada, tomando-se cuidado, com relação a essa última, de evitar provas que solicitem conhecimento exclusivo de ambientes sociais urbanos. Nesse sentido, utilizou-se o teste Matrizes Progressivas de Raven - Escala Colorida (Angelini, Alves, Custódio, Duarte \& Duarte, 1999) e os subtestes Dígitos, Códigos e Aritmética da Escala do WISC-III (Wechsler, 2002). A escolha dos subtestes Dígitos e Aritmética deve-se ao fato de esses subtestes verbais apresentarem itens de conteúdo familiar às crianças rurais graças à escola. O conteúdo de alguns itens dos outros subtestes, como Informação (ex. diga o nome de dois tipos de dinheiro), Semelhanças (ex. piano-violão) ou Compreensão (por que os carros devem ter cinto de segurança?), são extremamente alheios ao quotidiano ou ao habitat das crianças rurais da zona geográfica estudada.

\section{Procedimentos}

A coordenação geral do projeto (Escola de Enfermagem da UFMG) encarregou-se do transporte, da alimentação e do aluguel de uma casa no centro da vila para permanência da equipe de avaliação². Previamente, uma das autoras do presente trabalho encarregou-se do treinamento da equipe de alunos do curso de Psicologia, enquanto a outra autora se encarregou da condução da avaliação em campo. Na vila, a equipe de avaliação foi recebida pelas autoridades educacionais cientes da atividade a ser realizada em função da divulgação anteriormente feita pela coordenação geral do projeto.

Devido ao pouco tempo disponível para a realização do estudo, às condições precárias ou, por vezes, infra-estrutura insuficiente e à longa distância de cada zona rural, a coordenação da avaliação psicológica e a direção escolar julgaram possível somente avaliar os escolares do centro da vila e das zonas rurais periféricas 3, 4 e 7 (as zonas mais próximas do centro). Nas zonas 3 e 4 as aplicações ocorreram dentro da sala de aula e no dormitório dos professores. Na zona 7, a aplicação ocorreu na sala de aula e em três barracas externas à escola. No centro da vila, as avaliações ocorreram em salas de aula das duas únicas escolas. Todas as crianças foram avaliadas individualmente. Previamente às avaliações, a equipe de examinadores teve que realizar atividades lúdicas com as crianças a fim de favorecer um contato social que permitisse as testagens. Em todo o processo de avaliação, os professores das escolas auxiliaram no planejamento e na logística das atividades.

\section{Resultados}

A amostra foi agrupada em três grupos etários a fim de conferir maior força às análises posteriores (uma

$16{ }^{2}$ A participação do Laboratório de Avaliação das Diferenças Individuais no projeto foi aprovada pelo Departamento de Psicologia da UFMG em $10 / 11 / 2004$. 
criança foi excluída da análise por não ter respondido ao teste Raven). Na Tabela 1, são apresentados os resultados nos testes cognitivos, considerando média e desvio-padrão.

\section{Diferenças devido à idade}

Em geral, observa-se um progressivo aumento das pontuações médias nos testes cognitivos (à exceção de Códigos) conforme aumenta a idade nos grupos etários. Uma análise de variância para um fator indica haver diferenças significativas entre as faixas etárias no teste Raven $[F(2,142) 12,278$, valor- $p=0,000]$; na prova de Dígitos [ $F(2,142) 19,715$, valor- $p=0,000]$; na prova de Aritmética $[F(2,142) 34,264$ valor- $p=0,000]$ e na prova de Código $[F(2,142) 7,048$, valor- $p=0,001]$. No entanto o teste Levine para verificação de igualdade de variância entre os grupos acusou diferenças significativas nos resultados de Raven $(p=0,000)$, Aritmética $(p=0,001)$ e quase significativa em Código $(p=0,060)$.

Tais resultados refletem uma ocorrência de variabilidade diferenciada entre os grupos etários, ou seja, houve grupos etários com maior variabilidade que outros devido à presença de crianças com escore muito alto ou muito baixo para a idade cronológica. Corroborando essa inferência, a análise Post-Hoc Bonferroni - teste estatístico conservativo - indica não haver diferenças significativas no teste Raven entre os grupos das faixas etárias de oito a nove anos e de dez a onze anos de idade ( $p=0,095)$; tampouco houve diferenças significativas no subteste Código entre os grupos de seis a sete anos e de oito a nove anos de idade $(p=0,999)$.

Os resultados parecem indicar que as diferenças de desempenho no Teste Raven e na prova de Código não dependeram predominantemente do aumento cronológico.

\section{Distorção entre série e idade}

Considerando-se a observação da presença de crianças de idade avançada em séries escolares levantou-se a variável distorção entre série e idade. Esse tipo de levantamento era de especial importância, pois as subseqüentes análises podiam ser afetadas por essa variável. Observou-se que a partir dos oito anos de idade começava a distorção entre série e idade. A situação era mais dramática a partir dos nove anos de idade em que a maioria das crianças frequentava séries inferiores às esperadas para a idade cronológica (Tabela 2).

Considerando a alta distorção entre série e idade, principalmente a partir dos dez anos de idade, realizou-se uma análise de correlação parcial entre idade e testes cognitivos, controlando-se a variável série escolar, e entre série escolar e testes cognitivos, controlando-se a variável idade. Observou-se que, como esperado, o aumento da idade, quando controlada a série escolar, não acompanhou o desempenho progressivo no teste Raven $(r=0,02 ; p=0,979)$ e no subteste dígitos $(r=0,15$; $p=0,07)$. Mas encontrou-se associação significativa entre a idade e aritmética $(r=0,27 ; p=0,000)$; com código a associação foi negativa $(r=-0,19 ; p=0,02)$. Já a variável série escolar, quando controlada a idade, apresentou associação significativa com o desempenho em todos os testes cognitivos.

Esses resultados permitem inferir que, na amostra rural estudada, a uma maior pontuação nos testes cognitivos associa-se uma maior série escolar e vice-versa. Tal situação não é encontrada com relação à variável idade.

Considerando os resultados da análise Post-Hoc Bonferroni em que o grupo etário mais velho não se diferenciou do grupo etário mais novo, e partindo da observação da existência de uma profunda distorção

Tabela 1. Média (M) e desvio-padrão (DP) do escore total nos testes cognitivos por faixa etária.

\begin{tabular}{|c|c|c|c|c|c|c|c|c|c|}
\hline \multirow{2}{*}{ Idade } & \multirow{2}{*}{$n$} & \multicolumn{2}{|c|}{ Raven } & \multicolumn{2}{|c|}{ Aritmética } & \multicolumn{2}{|c|}{ Digitos } & \multicolumn{2}{|c|}{ Código } \\
\hline & & $M$ & DP & $M$ & DP & M & DP & M & DP \\
\hline $6-7$ & 53 & 11,91 & 3,01 & 8,60 & 3,79 & 6,92 & 2,77 & 22,06 & 9,52 \\
\hline $8-9$ & 52 & 14,17 & 2,97 & 11,67 & 2,73 & 8,25 & 2,07 & 20,71 & 7,81 \\
\hline $10-11$ & 38 & 16,00 & 5,82 & 13,87 & 2,18 & 10,11 & 2,19 & 27,95 & 11,10 \\
\hline Total & 143 & 13,82 & 4,24 & 11,12 & 3,70 & 8,25 & 2,68 & 23,13 & 9,80 \\
\hline
\end{tabular}


entre série e idade aos dez e onze anos de idade, considerou-se pertinente realizar uma análise de regressão das variáveis idade e série sobre o desempenho no teste Raven tanto no grupo mais novo quanto no mais velho. A hipótese era que no grupo mais novo a idade teria maior predição do desempenho cognitivo que a série escolar; no grupo mais velho, seria encontrado o inverso. Utilizou-se o método standard de regressão para análise das variáveis preditoras (Tabela 3).

No grupo da faixa etária de seis a nove anos de idade, o valor beta padronizado indica uma predição significativa apenas da variável idade $(\beta=0,249)$. Nesse grupo, as variáveis idade e série escolar explicam 10\% da variância no teste Raven $\left(R^{2}=0,103\right)$. Inversamente, e como esperado, no grupo da faixa etária de dez a onze

Tabela 2. Distorção entre série e idade.

\begin{tabular}{|c|c|c|c|}
\hline Idade & Série & $\%$ & Freqüências absolutas \\
\hline \multirow[t]{2}{*}{6 anos } & Pré-escola & 47,6 & 10 \\
\hline & 1a série & 52,4 & 11 \\
\hline \multirow[t]{2}{*}{7 anos } & 1a série & 90,9 & 30 \\
\hline & 2a série & 9,1 & 3 \\
\hline \multirow[t]{2}{*}{8 anos } & 1a série & 42,3 & 11 \\
\hline & 2a série & 57,7 & 15 \\
\hline \multirow[t]{3}{*}{9 anos } & 1a série & 38,5 & 10 \\
\hline & 2a série & 53,8 & 14 \\
\hline & 3a série & 7,7 & 2 \\
\hline \multirow[t]{4}{*}{10 anos } & 1a série & 5,9 & 1 \\
\hline & 2a série & 64,7 & 11 \\
\hline & 3a série & 17,6 & 3 \\
\hline & $4^{a}$ série & 11,8 & 2 \\
\hline \multirow[t]{5}{*}{11 anos } & 1a série & 9,5 & 2 \\
\hline & 2a série & 19,0 & 4 \\
\hline & 3a série & 14,3 & 3 \\
\hline & 4a série & 9,5 & 2 \\
\hline & 5a série & 47,6 & 10 \\
\hline
\end{tabular}

Tabela 3. Regressões de idade e série escolar nos dois grupos etários sobre o desempenho no teste Raven.

\begin{tabular}{llcccc}
\hline Grupo etário Preditores & B & SEB & $\beta$ & $\begin{array}{l}\text { Variância } \\
\text { explicada }\end{array}$ \\
\hline \multirow{2}{*}{ 6-9 anos } & Idade & 0,746 & 0,344 & $0,249^{*}$ & $R^{2}=0,103$ \\
& Série Escolar & 0,486 & 0,526 & 0,106 & \\
\multirow{2}{*}{10 - 11 anos } & Idade & 1,938 & 1,571 & 0,166 & $\Delta R^{2}=0,515$ \\
& Série Escolar & 2,706 & 0,571 & $0,638^{* *}$ & \\
\hline
\end{tabular}

$18 *(N=104, p<0,05) ; * *(N=37, p<0,001) ; \beta:$ Beta; SEB: Standard Error Beta anos, o valor beta padronizado indica uma forte predição apenas da variável série escolar ( $\beta=0,638)$. Nesse grupo, o valor do R corrigido, considerando o tamanho da amostra, mostra que ambas as variáveis explicam 51,5\% da variância no teste Raven (de $\Delta R^{2}=0,515$ ).

\section{Diferenças devido à localidade da escola}

Cogitou-se a possibilidade de que as crianças que freqüentavam a escola central da vila rural, embora todas provenientes de lares pobres, tivessem um desempenho diferenciado das crianças das zonas rurais periféricas por estarem um pouco mais expostas aos recursos de comunicação - telefone e televisão na escola - e de transporte - ônibus e carros. Para tanto, realizou-se uma análise de variância fatorial (two way) na qual os fatores idade e localidade ingressaram no modelo como variáveis independentes e o escore total no teste Raven como variável dependente. O resultado indicou diferenças significativas quando se considera a idade $[F(5,120) 5,259$, valor- $p=0,000]$, mas não se observaram diferenças significativas quando se considera a localidade da escola $[F(3,120) 1,577$, valor- $p=0,198]$. Entretanto a interação idade e escola tampouco foi significativa (valor- $p=0,213$ ). Portanto o efeito da idade nas diferenças de desempenho no teste Raven é o mesmo para crianças das diferentes escolas. O índice do Eta Quadrado mostra que 18,0\% da variância no teste Raven podem ser explicados pela idade. A localidade da escola explica apenas 3,8\% da variância. A predição da variância no desempenho do teste Raven por ambos fatores (idade e localidade da escola) corresponde a 0,268.

Esse resultado é particularmente interessante porque mostra que, apesar de as crianças terem um pouco de acesso aos recursos de comunicação e transporte, não se encontraram diferenças substantivas no rendimento intelectual entre as escolas. As crianças das escolas do centro da vila rural encontravam-se quase no mesmo patamar cognitivo que as crianças das escolas das zonas periféricas.

\section{Diferenças devido ao gênero}

Investigou-se a possibilidade de ocorrer diferenças cognitivas devido ao gênero. Para tanto, 
utilizou-se uma análise de variância univariada tendo como variável independente o gênero e como variáveis dependentes as pontuações no teste Raven Aritmética, Dígitos e Código. Os resultados de ANOVA para cada teste cognitivo apontaram não haver diferenças significativas entre os gêneros para nenhum dos testes cognitivos tanto no grupo etário de seis a sete anos quanto no grupo de oito a nove anos de idade. No caso do grupo etário de dez a onze anos de idade, identificaram-se diferenças significativas entre gêneros no teste Raven $[F(1,37) 6,103 ; p=0,018]$ e no subteste Código $[F(1,37)$ $11,127 ; p=0,02]$ a favor das meninas.

\section{Comparação de desempenho cognitivo entre crianças rurais e crianças urbanas}

Considerando que na amostra de estudo ocorreu forte associação entre série escolar e desempenho nos testes cognitivos, selecionou-se uma subamostra de crianças rurais que freqüentavam a série escolar esperada para a idade cronológica. $O$ desempenho dessa subamostra foi comparado ao de uma amostra de crianças urbanas de uma escola pública de Belo Horizonte. A testagem da amostra urbana ocorreu em 2002 e é parte de um projeto longitudinal de avaliação intelectual patrocinado pelo Laboratório de Avaliação das Diferenças Individuais. Na amostra urbana não se aplicou Código, razão pela qual essa prova não fez parte das análises. A faixa etária possível de comparação foi a de sete a oito anos de idade (média $=7,44 ; \mathrm{DP}=0,50$; $\mathrm{n}=59$ na amostra rural e média $=7,51 ; \mathrm{DP}=0,50$ na amostra urbana; $n=143$ ). As crianças de ambas as amostras freqüentavam a primeira e a segunda séries do ensino fundamental, sendo a maioria estudantes da primeira série escolar (69,5\% da amostra rural e 58,0\% da amostra urbana). As estatísticas descritivas de ambas as amostras relacionadas ao desempenho cognitivo são apresentadas na Tabela 4.

Tabela 4. Estatística descritiva do desempenho cognitivo de cada amostra.

\begin{tabular}{lcccccc}
\hline \multirow{2}{*}{ Teste } & \multicolumn{2}{c}{ Rural $(n=59)$} & & \multicolumn{2}{c}{ Urbana $(n=143)$} \\
\cline { 2 - 3 } \cline { 5 - 6 } & $M$ & $D P$ & & $M$ & DP \\
\hline Raven & 12,92 & 3,22 & & 22,95 & 5,58 \\
Dígitos & 7,66 & 2,77 & & 10,33 & 2,35 \\
Aritmética & 10,31 & 3,61 & & 13,19 & 2,26 \\
\hline
\end{tabular}

M: média; DP: desvio-padrão.
Antes de proceder à comparação de médias, correlacionou-se a pontuação dos três testes cognitivos em cada grupo. O intuito era verificar a homogeneidade do comportamento intelectual. Os resultados indicaram associações significativas entre todos os subtestes. Especificamente a associação entre Raven e Dígitos foi de 0,341 para a amostra rural e de 0,426 para a amostra urbana. A associação entre Raven e Aritmética foi de 0,464 para a amostra rural e de 0,497 para a amostra urbana. A associação entre Dígitos e Aritmética foi de 0,595 para a amostra rural e de 0,371 para a amostra urbana. Nesse sentido, pode-se inferir que o comportamento intelectual de cada amostra foi homogêneo com relação aos testes cognitivos.

Utilizou-se uma análise de variância univariada para cada teste cognitivo a fim de identificar diferenças cognitivas significativas entre as amostras. A análise apontou diferenças no teste Raven $[F(1,201) 167,42$; $p=0,000]$, em Dígitos [F(1,201) 48,30; $p=0,000]$ e em Aritmética [F(1,201) 46,98; $p=0,000]$. A observação das estatísticas descritivas mostra que as médias da amostra urbana são bastante superiores às médias da amostra rural.

Uma forma de observar a equivalência em QI das diferenças observadas entre as amostras é calcular o índice $d$ (diferenças expressas em unidades de desvio-padrão), multiplicando-o por 15. Para obter o índice $d$ se subtrai a média do primeiro grupo da média do segundo grupo e se divide o valor obtido pela média dos desvios-padrão de ambos os grupos (Jensen, 1998; pág. 403). A fórmula para tal cálculo é:

$$
\left.d=\left[\square_{a}-\square_{b}\right] / \sqrt{ }\left[\left(N_{a} \sigma_{a}^{2}+N_{b} \sigma_{b}^{2}\right) / N_{a}+N_{b}\right)\right],
$$

onde $\square$ é a média, N é o tamanho da amostra e $\sigma$ é o desvio-padrão. A Tabela 5 apresenta os índices $d$ para cada teste cognitivo e seu equivalente em QI.

Os resultados mostram, em primeiro lugar, que há superioridade cognitiva da amostra urbana em relação à amostra rural. Em segundo lugar, que a

Tabela 5. Índices d e equivalência em QI.

\begin{tabular}{lcc}
\hline Teste & $d$ & Ql \\
\hline Raven & $-2,001$ & 30,00 \\
Dígitos & $-1,077$ & 16,50 \\
Aritmética & $-1,058$ & 15,87 \\
\hline
\end{tabular}


diferença entre as amostras no teste de inteligência fluida (Raven) é quase o dobro da diferença obtida nos subtestes de inteligência cristalizada (Dígitos e Aritmética). Considerando que a distribuição intelectual compreende variabilidade em desvio-padrão de 15 pontos, os resultados aqui apresentados mostram distâncias entre 1 e 2 desvios-padrão entre a amostra urbana e a amostra rural.

\section{Discussão e Conclusão}

Vários pontos de interesse devem ser destacados. Em primeiro lugar, quando se considera a amostra total de crianças de zona rural não se encontra associação positiva entre idade e QI. Esse tipo de resultado pode ser encontrado em pesquisas antigas sobre comunidades isoladas da Inglaterra e dos Estados Unidos na primeira metade do século passado (Butcher, 1972). Nesses estudos, observou-se uma correlação negativa entre idade e Ql em grupos de crianças. $\mathrm{O}$ índice era maior em comunidades de menor contato social e vice-versa: a correlação negativa entre idade e Ql era menor em comunidades que permitiam maiores contatos sociais.

Entretanto quando se considera o padrão cognitivo de crianças de maior idade com sérios problemas de distorção entre série e idade e o de crianças novas freqüentando a série escolar esperada da zona rural, as análises de regressão indicam que, nas crianças de maior idade (dez a onze anos de idade), a série escolar prediz fortemente o desempenho nos testes (51\% da variância) e não a idade cronológica. A situação se inverte no grupo de crianças novas, em que a idade prediz melhor o desempenho nos testes (10\% da variância) e não a série escolar.

Por que a idade cronológica não acompanha o aumento no desempenho dos testes de inteligência no grupo de crianças de maior idade enquanto a escolaridade o faz? Existem duas vias opostas de explicação. A primeira recorre a uma revisão clássica realizada por Ceci (1991) sobre escolaridade e QI. Segundo essa revisão, o QI sofre efeitos negativos de variáveis ambientais, como a freqüência escolar intermitente, o início tardio ou o término precoce da escolaridade. Embora o presente estudo não tenha levantado o índice de absenteísmo

20 escolar, dada a inexistência desse tipo de registro nas escolas das zonas periféricas, a distorção entre série e idade constitui uma evidência de irregularidade no período da escolaridade das crianças com maior idade, podendo-se alegar, portanto, que fatores ambientais têm um peso decisivo sobre o Ql (Tabela 2).

Contudo a outra via também é plausível, isto é, a correlação positiva e significativa entre escolaridade e Ql em crianças com maior idade $(r=0,638)$ pode significar que as crianças que obtiveram maior QI são aquelas que conseguiram obter maior sucesso escolar, sobrepondo-se ao efeito da maturação cuja variabilidade era bastante reduzida no grupo (apenas dez e onze anos). Nesse sentido, os resultados acompanham o conhecimento de que a associação entre nível educativo e inteligência é de 0,55, sendo ela menor nos primeiros anos de escolaridade (Gottfredson, 1997; Jensen, 1998).

Em segundo lugar, com relação a diferenças de gênero, os resultados mostraram o mesmo padrão registrado na literatura. As diferenças oscilam bastante na infância, havendo uma tendência para pontuações superiores das meninas aos dez e onze anos de idade (Lynn \& Irving, 2004).

O terceiro ponto e que constitui o resultado mais preocupante, pela sua repercussão social, é a diferença de desempenho cognitivo entre crianças rurais e crianças urbanas. A explicação não pode estar na falta de entendimento das crianças rurais do que venha a ser um teste psicológico, pois 1) as amostras de comparação estavam igualadas em idade e série escolar, 2) as crianças da amostra urbana não tinham idade suficiente para ter, por exemplo, ampla experiência de testagem e, 3) os índices de correlação entre os resultados das provas cognitivas mostraram que ambas as amostras comportaram-se de maneira semelhante. As diferenças podiam estar muito provavelmente relacionadas ao grau de estimulação cognitiva e de cuidado nutricional recebido de forma diferenciada por ambas amostras antes do início formal da escolarização.

O amplo estudo de Gomes-Neto et al. (1997) em áreas rurais do Ceará, por exemplo, mostrou que 15\% dos alunos tinham desnutrição crônica, 32\% eram severamente desnutridos e 45\% tinham alguma deficiência visual. Essa condição de nutrição e de saúde geral dos alunos rurais estava significativamente relacionada ao desempenho escolar. No presente estudo, a amostra rural pertence a uma área endêmica, em que a maioria 
dos habitantes está infectada por um tipo de verminose que se propaga predominantemente em áreas sem condições sanitárias, não urbanas e em que, provavelmente, as pessoas andam descalças. Já a amostra urbana freqüenta uma escola pública bastante procurada pelas famílias de Belo Horizonte, com regular suporte médico, social e educativo devidos à sua inserção na universidade. Nesse sentido, é razoável supor que existam diferenças de nutrição e estimulação cognitiva entre as amostras (rural e urbana) desde antes do ingresso à escola e que essas diferenças seriam as que acompanham a variação intelectual das amostras.

Cognitivamente, a diferença é mais intensa no teste Raven (30 pontos de QI), uma medida de inteligência fluida, do que nos subtestes do WISC-III (média de 16,19 pontos de Ql), conhecidos como medidas de inteligência cristalizada. Curiosamente, esse padrão de diferenças é o mesmo que se encontra nos estudos de diferenças cognitivas entre gerações. A literatura apresenta discordância quanto à natureza dos ganhos. Rushton (1999), analisando dados de padronização do WISC, alega que os ganhos de QI correspondem a ganhos de inteligência cristalizada (relacionada com educação e cultura) e não do fator g (ou seu similar "inteligência fluida"), razão pela qual o autor afirma que o ambiente não teria alterado a inteligência humana propriamente dita.

Flynn (1999), ao reanalisar os dados de Rushton (1999) e considerando os subtestes do WISC que maior associação apresentam com o Raven, encontrou correlação positiva entre ganhos de Ql e inteligência fluida. O autor conclui que o aumento intelectual corresponde ao aumento da inteligência fluida e que o ambiente é o principal responsável. No caso das diferenças cognitivas intragerações, os resultados da presente investigação mostram que ambientes rurais, extremamente alheios aos avanços de comunidades urbanas, afetam com maior intensidade a inteligência fluida do que a inteligência cristalizada. É possível, portanto, que tanto a hipótese nutricional quanto a hipótese de estimulação cognitiva sejam ambas as responsáveis pelas mudanças de Ql na população humana.

Em países desenvolvidos, é difícil encontrar comunidades rurais com índice baixo de desenvolvimento humano. A evidência do papel ambiental, portanto, pode ser encontrada em países em desenvolvimento. Contudo cabe destacar a variabilidade de desenvolvimento social existente entre as zonas rurais no Brasil. A zona rural que foi estudada no presente estudo mostra índices de desenvolvimento humano muito baixos. É provável, nesse sentido, que outras zonas rurais, dependendo do seu grau de avanço social, apresentem também taxas diferenciadas de desenvolvimento cognitivo, à semelhança dos resultados obtidos por Alderman et al. (1996). Os dados aqui mostrados refletem o impacto no desenvolvimento cognitivo da população infantil de um ambiente social extremamente precário. Trata-se de um tipo de informação psicológica que deve ser levado em consideração nas políticas de intervenção governamental.

Deve-se registrar, contudo, que a presente investigação tentou quantificar, pela primeira vez na literatura nacional, a fenda cognitiva existente entre crianças de zona rural e de zona urbana. Contudo ela não sistematizou informações que poderiam aumentar a compreensão das diferenças cognitivas. Essas informações se referem a medidas antropométricas, que forneceriam um índice nutricional individual preciso e entrevistas com os pais, que forneceriam dados sociofamiliares mais detalhados. Sugere-se que em próximas pesquisas ambas variáveis sejam, de fato, controladas.

\section{Referências}

Alderman, H., Behrman, J. R., Khan, S., Ross, D. R., \& Sabot, R. (1996). Decomposing the regional gap in cognitive skills in rural Pakistan. Journal of Asian Economics, 7 (1), 49-76.

Angelini, A. L., Alves, I. C. A., Custódio, E. M., Duarte, W. F., \& Duarte, J. L. M. (1999). Manual das matrizes progressivas de Raven. São Paulo: Centro Editor de Testes e Pesquisas em Psicologia.

Butcher, H. J. (1972). A inteligência humana. São Paulo: Perspectiva.

Carelli, A. (1994). O caráter urbano da habilidade mental. Boletim de Psicologia, 44 (100/101), 15-19.

Cattell, R. B. (1971). Abilities: their structure, growth, and action. Boston: Houghton Miflin.

Ceci, S. (1991). How much does schooling influence general intelligence and its cognitive components? A reassessment of the evidence. Developmental Psychology, 27 (5), 703-722. 
Fahrmier, E. D. (1975). The effect of school attendance on intellectual development in Northern Nigeria. Child Development, 46, 281-285.

Flores-Mendoza, C. E. (2006). O estudo das diferenças individuais no Brasil. In C. Flores-Mendoz, R. Colom, A. Andrés-Pueyo, R. J. Haier \& S. A. Petrill. Introdução à Psicologia das diferenças individuais (pp.37-56). Porto Alegre: ArtMed.

Flynn, J. R. (1999). Evidence against Rushton: the genetic loading of WISC-R subtests and the causes of betweengroup IQ differences. Personality and Individual Differences, 26, 373-379.

Flynn, J. R. (2003). Movies about intelligence: the limitations of 9 . Current Directions in Psychology, 12, 95-99.

Flynn, J. R. (2006). O efeito Flynn: repensando a inteligência e aquilo que a afeta. In C. Flores-Mendoz, R. Colom, A. Andrés-Pueyo, R. J. Haier \& S. A. Petrill. Introdução à Psicologia das diferenças individuais (pp.387-411). Porto Alegre: ArtMed.

Glewwe, P., \& Jacoby, H. (1992). Estimating the determinants of cognitive achievement in low-income countries. The case of Ghana. Washington (DC): The World Bank.

Gomes-Neto, J. B., Hanushek, E. A., Leite, R. H., \& Frota-Bezzera. (1997). Health and schooling: evidence and policy implications for developing countries. Economics of Educational Review, 16 (3), 271-282.

Gottfredson, L. S. (1997). Why g matters: the complexity of everyday life. Intelligence, 24, 79-132.

Instituto Brasileiro de Geografia e Estatística. Ministério do Planejamento, Orçamento e Gestão. Departamento de População e Indicadores Sociais. (2000). Disponível em: www.ibge.gov.br

Jensen, A. R. (1998). The g factor. The science of mental ability. London: Praeger.
Lynn, R., \& Vanhanen, T. (2002). IQ and the wealth of nations. London: Praeger.

Lynn, R., \& Irwing, P. (2004). Sex differences on the progressive matrices: a meta-analysis. Intelligence, 32, 481-498.

Neisser, U. (1998). Therising curve. Washington, DC: American Psychological Association.

Neisser, U., Boodoo, G., Bouchard, T., Boykin, A., Brody, N., Ceci, S., Halpern, D., Loehlin, J., Perloff, R., Sternberg, R., \& Urbina, S. (1996). Intelligence: knowns and unknowns. American Psychologist, 51 (2), 77-101.

Rushton, J. P. (1999). Secular gains in IQ not related to the $g$ factor and inbreeding depression -unlike black-white differences: a reply to Flynn. Personality and Individual Differences, 26, 381-389.

Sigman, M., \& Whaley, S.E. (1998). The role of nutrition in the development of intelligence. In U. Neisser (Org.), The Rising Curve. Washington, DC:American Psychological Association.

Sternberg, R. J., Nokes, C., Geissler, L. W., Prince, R., Okatcha, E., Bundy, D. A., \& Grigorenko, E. L. (2001). The relationship between academic and practical intelligence: a case study in Kenya. Intelligence, 29, 401-418.

Wechsler, D. (2002). WISC: escala de inteligência para crianças: manual (3a.ed.). Adaptação e padronização para uma amostra brasileira realizada por Vera Lúcia Marques de Figueiredo. São Paulo: Casa do Psicólogo.

William, W. M. (1998). Are we raising smarter children today? school- and home-related influences on IQ. In U. Neisser (Org.), The rising curve. Washington, DC: American Psychological Association.

Recebido em: 2/3/2006

Versão final respresentada em: 26/7/2006

Aprovado em: 15/9/2006 